\title{
Short communication: Evaluation of bulk tank milk microbiological quality of nine dairy farms in Tennessee
}

\author{
B. E. Gillespie, ${ }^{\star}$ M. J. Lewis, ${ }^{*}$ S. Boonyayatra,† M. L. Maxwell, ${ }^{*}$ A. Saxton, ${ }^{\star}$ S. P. Oliver, ${ }^{\star}$ and R. A. Almeida ${ }^{* 1}$ \\ *Department of Animal Science, The University of Tennessee, Knoxville 37996 \\ †Veterinary Medicine, Chiang Mai University, Chiang Mai, Thailand 50100
}

\begin{abstract}
The purpose of this study was to evaluate the bulk tank milk (BTM) quality of 9 East Tennessee dairy farms and to determine its relationship with selected quality milk parameters. Bulk tank milk samples ( $\mathrm{n}=$ 1,141) were collected over a 42-mo period (June 2006 through November 2009) from farms, based on their preliminary incubation count (PIC) history. Parameters of BTM quality evaluated in this study included somatic cell count (SCC), standard plate count (SPC), PIC, laboratory pasteurization count (LPC), Staphylococcus spp. count, Streptococcus spp. count, and coliform count. Strong correlations between SPC and Streptococcus spp. counts (0.72) and between SPC and PIC (0.70) were found. However, moderate correlations were seen among other milk quality parameters. In addition, seasonal variations for some milk quality parameters were noted. For example, milk quality parameters such as SCC, SPC, LPC, and coliform count were significantly higher in summer, whereas Streptococcus spp. counts were significantly higher in winter. No seasonal variation in PIC or Staphylococcus spp. counts was observed. Summarizing, results from this investigation showed the importance of using several bacterial counts (SCC, SPC, PIC, LPC, Streptococcus spp. count, Staphylococcus spp. count, and coliform counts) as simultaneous indicators of milk quality.
\end{abstract}

Key words: milk quality, bulk tank milk analysis, somatic cell count

\section{Short Communication}

Bulk tank milk (BTM) analysis is used by dairy producers, dairy processors, veterinarians, and dairy researchers as an indicator of milk quality. Parameters of milk quality evaluated most often include SCC, SPC, and preliminary incubation count (PIC). Other parameters of milk quality that may be used include

Received August 29, 2011

Accepted April 13, 2012.

${ }^{1}$ Corresponding author: ralmeida@utk.edu laboratory pasteurization count (LPC), Staphylococcus spp. count, Streptococcus spp. count, and coliform count. The Pasteurized Milk Ordinance has set regulatory standards for total bacteria counts in grade A milk as $<100,000 \mathrm{cfu} / \mathrm{mL}$. The Pasteurized Milk Ordinance (http://www.fda.gov/downloads/Food/FoodSafety/ Product-SpecificInformation/MilkSafety/NationalConferenceonInterstateMilkShipmentsNCIMSModelDocuments/UCM209789.pdf) also had set regulatory standards for SCC as $<750,000$ cells $/ \mathrm{mL}$; however, the US Department of Agriculture's Agricultural Marketing Service (AMS) announced updates to the European Health Certification Program, establishing a 400,000SCC limit for all milk and dairy products exported to the European Union. Many milk processors reward dairy producers with a premium for high-quality milk based on one or more of these parameters. Although regulatory standards only exist for SPC and SCC, PIC is often used by some milk processing plants as an indicator of milk quality and shelf life of pasteurized milk. High bacteria counts in BTM affect the quality of pasteurized milk and milk products by decreasing the shelf life and producing off-flavors (Barbano et al., 2006). The SCC has been widely used to indicate the prevalence of IMI in dairy herds. Bulk tank milk with high SCC has a higher level of proteolytic and lipolytic enzymes, which affect the flavor and shelf life of dairy products (Barbano et al., 2006). The SPC provides an estimate of the total number of aerobic bacteria present in raw milk, and high SPC results indicate cows infected with mastitis or poor cow preparation, which means unsanitary milking and cleaning protocol. The PIC measures the number of psychrotrophic bacteria that grow at $12.8^{\circ} \mathrm{C}$ or suboptimal refrigeration temperature and it is usually taken as an indication of poor on-farm sanitation and milk production practices. The PIC is usually higher than the SPC; however, a PIC of 3 to 4 times greater that the SPC is considered extremely elevated (Jayarao et al., 2004). The LPC measures the thermoduric bacteria that survive laboratory pasteurization and is used as an indicator of milking equipment sanitation. Coliforms are regularly found in manure, bedding material, soil, and contami- 
nated water (Elmoslemany et al., 2009b). Guidelines for monitoring BTM for milk quality parameters have been described by Jayarao et al. (2004). The purpose of this study was to evaluate several dairy farms for these indicators of milk quality over time and to determine what relationship exists between these parameters and BTM quality.

All farms involved in the study were associated with a milk buyer who sells milk to processing plants with a premium PIC program. In this PIC program, a premi$\mathrm{um}$ is given to farms with PIC $<10,000 \mathrm{cfu} / \mathrm{mL}$. Farms were selected based on their PIC history over the past 2 yr. Farms with a PIC consistency $<10,000 \mathrm{cfu} / \mathrm{mL}$ $(\mathrm{n}=3)$, farms with PIC values that fluctuated above and below 10,000 $\mathrm{cfu} / \mathrm{mL}(\mathrm{n}=3)$, and farms with consistently high PIC ( $\mathrm{n}=3$ ) were chosen. Bulk tank milk samples were collected from these dairy farms in East Tennessee over a 3.5-yr period (June 2006 through November 2009). Samples were collected weekly for 2 yr and every 2 wk for the following 18 mo. Bulk tank milk samples were collected by field personnel, stored on ice, and delivered to the laboratory between 0 to $3 \mathrm{~d}$ after collection. At the laboratory, samples were analyzed for SCC, SPC, PIC, LPC, Staphylococcus spp. count, Streptococcus spp. count, and coliform count. The number of somatic cells in milk was determined by the DHIA Laboratory (Knoxville, TN) using the Somacount 300 (Bentley Instruments Inc., Chaska, MN). Petrifilm Aerobic Count Plates (3M US, St. Paul, MN) were used for SPC, PIC, and LPC, following procedures recommended by the American Public Health Association (Wehr and Frank, 2004). Petrifilms were read using an automated counter (3M Petrifilm Plate Reader; 3M US). For Staphylococcus spp., Streptococcus spp., and coliform counts, procedures outlined by Jayarao et al. (2004) with modifications were used. Colonies suggestive of Streptococcus agalactiae were further characterized by serotyping (Streptex; Remel Products, Lenexa, KS) and identified to the species level by API 20 STREP (bioMérieux Inc., Hazelwood, $\mathrm{MO}$ ). For coliform counts, $1 \mathrm{~mL}$ of milk was used for MacConkey agar (Becton, Dickinson and Co., Franklin Lakes, NJ) pour plates.

To identify bacteria contributing to PIC counts, Petrifilms with $>10,000 \mathrm{cfu} / \mathrm{mL}$ were plated on tryptic soy agar with 5\% sheep blood (BAP; Becton, Dickinson and Co.) and bacteria were identified using standard microbiological procedures as outlined by the National Mastitis Council Inc. (Verona, WI; Oliver et al., 2004).

Milk quality data were log transformed to correct positively skewed variables. Analysis of variance was used to test for producer, season, and year differences. Least squares means were compared using the Fisher least significant difference test where ANOVA differ- ences were detected. All statistical analyses were run using SAS software (SAS Institute Inc., Cary, NC) at the $5 \%$ significance level. Bulk tank milk samples were separated into seasons according to traditional designations: spring (March 21 to June 20), summer (June 21 to September 20), fall (September 21 to December 20), and winter (December 21 to March 20).

The herd size averaged 118 head for all 9 farms, with a range from 36 to 185 head for the smallest and the largest herd, respectively. The average milk yield produced per milking was $1,750 \mathrm{~kg}$, with a range of 295 $\mathrm{kg}$ for the smallest herd ( 36 head) to $4,173 \mathrm{~kg}$ for the largest herd (185 head). Results of the BTM analysis indicated that the 9 dairy farms had an average SCC for the 42 -mo period of $4.7 \times 10^{5}$ cells $/ \mathrm{mL}$, well above the average SCC reported for Tennessee during 2006 through $2009\left(4.6 \times 10^{5}, 4.1 \times 10^{5}, 3.6 \times 10^{5}\right.$, and 3.7 $\times 10^{5}$ cells $/ \mathrm{mL}$, respectively; Miller et al., 2007, 2008; Norman et al., 2009, 2010). Eight of the 9 farms had SCC $>7.5 \times 10^{5}$ cells $/ \mathrm{mL}$ at least 6 times over the 42 mo period. A seasonal effect was seen with SCC counts, with the highest counts in summer and lowest SCC in winter (Figure 1A).

The mean SPC for these herds was $5.0 \times 10^{3} \mathrm{cfu} / \mathrm{mL}$. All 9 farms had SPC $>100,000 \mathrm{cfu} / \mathrm{mL}$ at least twice over the 42-mo period, and 1 farm had SPC $>1.0 \times 10^{5}$ $\mathrm{cfu} / \mathrm{mL} 7$ times over that same period. The SPC was higher in summer and winter (Figure 1B). Correlation coefficients among milk quality parameters were evaluated and the highest correlations were between SPC and Streptococcus spp. counts (0.72) and between SPC and PIC (0.70).

The mean LPC for the herds in this study was $4.3 \times$ $10^{1} \mathrm{cfu} / \mathrm{mL}$, indicating good cleaning and sanitation of the milking system. Laboratory pasteurization counts between 100 and $200 \mathrm{cfu} / \mathrm{mL}$ indicates adequate cleaning and sanitation of the milking system (Jayarao et al., 2004; Elmoslemany et al., 2009a). The LPC was significantly lower $(P<0.05)$ in spring than other seasons and was highest in summer and fall (Figure 1C).

Preliminary incubation counts for the 9 farms ranged from $1.8 \times 10^{2}$ to $1.3 \times 10^{7} \mathrm{cfu} / \mathrm{mL}$ for the same time. In this study, no seasonal differences were seen with the PIC (Figure 1D). Evaluation of PIC Petrifilms with counts $>1.0 \times 10^{4} \mathrm{cfu} / \mathrm{mL}$ revealed that a wide variety of bacteria that contributed to PIC, including Staphylococcus aureus, CNS, Streptococcus dysgalactiae, Streptococcus uberis, Aerococcus spp., Enterococcus spp., Lactococcus spp., Escherichia coli, Enterobacter cloacae, Klebsiella spp., Corynebacterium spp., Pantoea spp., Pseudomonas spp., Proteus spp., Rhodococcus spp., and Bacillus spp. Some PIC films had a predominant bacteria present, which was determined by growth in high numbers in the $10^{-3}$ dilution. Predomi- 

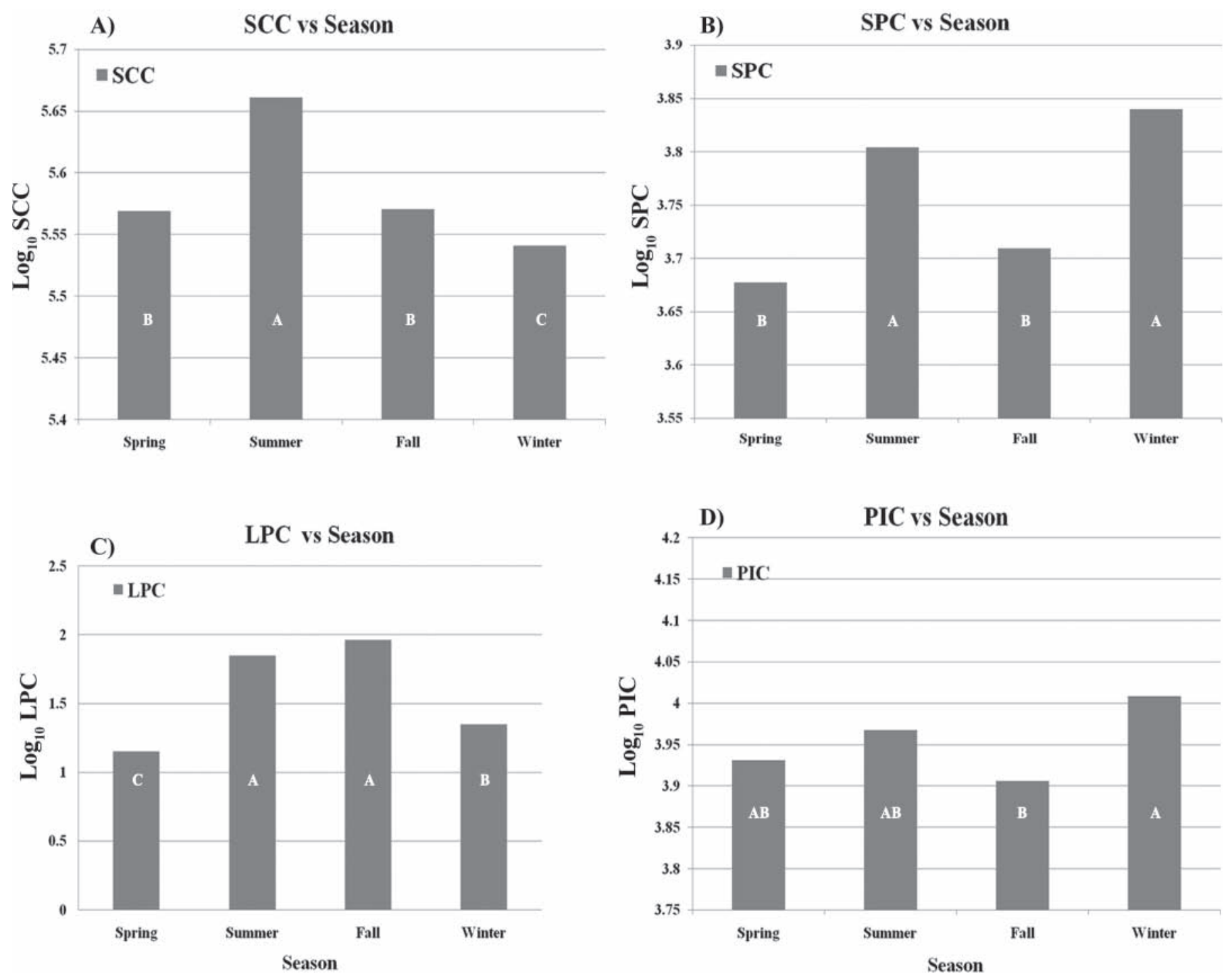

Figure 1. (A) Average SCC by season, (B) average standard plate count (SPC) by season, (C) average laboratory pasteurization count (LPC) by season, and (D) average preliminary incubation count (PIC) by season. Columns with different letters (A-C) are statistically different $(P<0.001)$.

nant bacteria were identified in $85 \%(463 / 541)$ of PIC Petrifilms from BTM (Table 1). Predominant bacteria from PIC Petrifilms from samples with PIC $<1.0 \times 10^{4}$ and $>1.0 \times 10^{4} \mathrm{cfu} / \mathrm{mL}$ were streptococci and similar species at 59 and $56 \%$, respectively. Coliforms were the next highest with $23 \%$ for PIC $<1.0 \times 10^{4} \mathrm{cfu} / \mathrm{mL}$ and $26 \%$ for PIC $>1.0 \times 10^{4}$. Gram-negative rods (noncoliforms) and Pseudomonas species were seen at $8 \%$ for PIC $<1.0 \times 10^{4} \mathrm{cfu} / \mathrm{mL}$ and $15 \%$ for PIC $>1.0 \times 10^{4}$ $\mathrm{cfu} / \mathrm{mL}$. Staphylococcus species and gram-positive rods were identified at a much lower percentage of 8 and $2 \%$ for Staphylococcus species and 2 and 1\% for grampositive rods, respectively. Staphylococcus aureus and coagulase-negative Staphylococcus species were rarely the predominant bacteria present in PIC; however, they were isolated routinely from PIC in low numbers.

The range of Staphylococcus spp. counts for these 9 farms ranged between $7.5 \times 10^{1}$ and $3.0 \times 10^{4} \mathrm{cfu} /$ $\mathrm{mL}$, with little variation observed for individual farms over the 42-mo period. No significant differences were seen with the Staphylococcus spp. counts over the 4 seasons. Staphylococcus aureus was detected in $89 \%$ of BTM samples during the same time period. The range of Streptococcus spp. counts for the 9 farms ranged between $1.0 \times 10^{1}$ and $2.2 \times 10^{5} \mathrm{cfu} / \mathrm{mL}$ and were highest in winter. Streptococcus spp. counts for these 9 farms varied considerably. Streptococcus agalactiae was detected from 2 farms during this time period. One 
Table 1. Predominant bacteria isolated from preliminary incubation count (PIC) Petrifilms (3M US, St. Paul, MN)

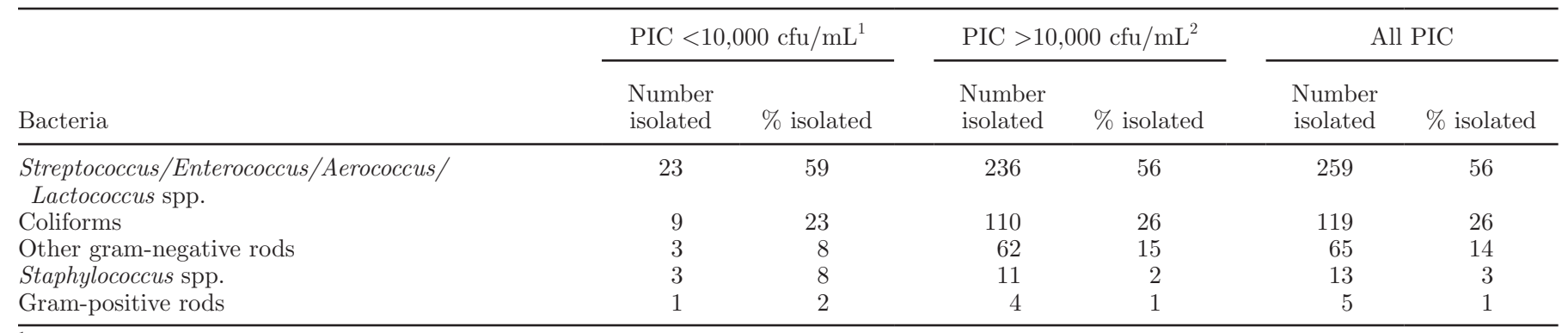

${ }^{1}$ Mean PIC 4,969 cfu/mL.

${ }^{2}$ Mean PIC 244,954 cfu/mL.

farm had a single isolation of Strep. agalactiae, whereas another farm had Strep. agalactiae isolated from April 2008 through November 2009. Coliform counts for all farms ranged between 0 and $8.4 \times 10^{4} \mathrm{cfu} / \mathrm{mL}$. Counts for coliforms were significantly higher $(P<0.065)$ in summer than any other seasons.

Seasonal trends in several of the milk quality parameters have been reported (Nightingale et al., 2008; Elmoslemany et al., 2009a; Pantoja et al., 2009). In this study, seasonal trends in SCC were observed with the highest values in summer months and the lowest during winter months. In other regions of the United States and Canada, higher SCC values have also been reported in summer months (Nightingale et al., 2008; Elmoslemany et al., 2009a; Pantoja et al., 2009). In a study conducted in Canada (Elmoslemany et al., 2009a), the total aerobic count tended to be higher in summer months. The total aerobic count is comparable to the SPC in the current study, which was higher in summer and winter than in spring and fall. Although no seasonal effect was observed with PIC, others (Elmoslemany et al., 2009a; Pantoja et al., 2009) have reported that PIC tended to be lower in winter months. The LPC was significantly lower in spring than other seasons and was highest in summer and fall. This was not observed in the study by Elmoslemany et al. (2009a) where no seasonal effect was seen with LPC; however, LPC tended to be lower in winter. Coliform counts have been reported by others (Elmoslemany et al., 2009a; Pantoja et al., 2009) to be higher in summer as was seen in the current study.

Correlation among BTM quality parameters were observed among several parameters. High correlations between SPC and PIC have been observed by other researchers (Jayarao et al., 2004; Elmoslemany et al., 2009a). In a study conducted in Pennsylvania, (Jayarao et al., 2004) high correlations were observed between SPC and PIC (0.62), LPC (0.51), Streptococcus spp. count (0.65), and Staphylococcus spp. counts (0.57) and between PIC and LPC (0.50) and Streptococcus spp. counts (0.53) and was similarly seen in this study. Correlation coefficients among other parameters were low $(<0.40)$ and this was observed by others (Pantoja et al., 2009; Elmoslemany et al., 2010).

In this study, farms were selected based on their PIC history over previous $2 \mathrm{yr}$. Interesting to note, the 3 farms chosen at the start of study with PIC $<1.0 \times$ $10^{4} \mathrm{cfu} / \mathrm{mL}$ remained the 3 farms with the lowest PIC. Two farms with consistently high PIC were the 2 farms with the highest PIC over that same time period. When other milk quality parameters were evaluated in relation to the grouping based on PIC, the 3 farms with the lowest PIC $\left(<1.0 \times 10^{4} \mathrm{cfu} / \mathrm{mL}\right)$ had the lowest SPC, LPC, Staphylococcus spp. count, and Streptococcus spp. count. In relation to the SCC and grouping based on PIC, significant difference was detected among the 3 groups. The group that had the lowest SCC had the highest PIC, LPC, and coliform count, suggesting that on-farm sanitation and milk production practices on the farm were the culprit, and not mastitis cases, because the SCC was the lowest of all groups.

Preliminary incubation counts measures the number of psychrotrophic bacteria present in BTM. The most commonly occurring psychrotrophs reported were gram-negative rods, of which Pseudomonas spp. account for approximately 50\% (Cousin, 1982). Gram-positive bacteria, such as Streptococcus and Enterococcus spp., have also been reported part of the psychrotrophic bacteria flora (Cousin, 1982). In this study, streptococci and similar species were the predominant bacteria, coliforms were next highest. Gram-negative rods (noncoliforms), Pseudomonas spp., Staphylococcus spp., and gram-positive rods were identified at much lower rates.

The results of this study provide a snapshot of the quality of bulk tank milk from 9 Tennessee dairy farms. The study illustrates the importance of using several bacterial counts (SCC, SPC, PIC, LPC, Streptococcus spp. count, Staphylococcus spp. count, and coliform count) as indicators of milk quality. Strong correlations were associated between PIC and SPC. Seasonal 
variations were noted for some milk quality parameters. Milk quality parameters such as SCC, SPC, LPC, and coliform count were significantly higher in summer, whereas Streptococcus spp. counts were significantly higher in winter. In general terms, BTM analysis gives a snapshot of milk quality and provides producers with valuable information concerning the status of health and sanitation in their herds.

\section{ACKNOWLEDGMENTS}

The authors acknowledge Piedmont Milk Sales Inc. (Blountville, TN) for their participation and support of this project.

\section{REFERENCES}

Barbano, D. M., Y. Ma, and M. V. Santos. 2006. Influence of raw milk quality on fluid milk shelf life. J. Dairy Sci. 89(E.-Suppl.):E15E19.

Cousin, M. A. 1982. Presence and activity of psychrotrophic microorganisms in milk and dairy products: A review. J. Food Prot. 45:172-207.

Elmoslemany, A. M., G. P. Keefe, I. R. Dohoo, and R. T. Dingwell. 2009a. Microbiological quality of bulk tank raw milk in Prince Edward Island dairy herds. J. Dairy Sci. 92:4239-4248.

Elmoslemany, A. M., G. P. Keefe, I. R. Dohoo, and B. M. Jayarao. 2009b. Risk factors for bacteriological quality of bulk tank milk in
Prince Edward Island dairy herds. Part 2: Bacteria count-specific risk factors. J. Dairy Sci. 92:2644-2652.

Elmoslemany, A. M., G. P. Keefe, I. R. Dohoo, J. J. Wichtel, H. Stryhn, and R. T. Dingwell. 2010. The association between bulk tank milk analysis for raw milk quality and on-farm management practices. Prev. Vet. Med. 95:32-40.

Jayarao, B. M., S. R. Pillai, A. A. Sawant, D. R. Wolfgang, and N. V. Hegde. 2004. Guidelines for monitoring bulk tank milk somatic cell and bacterial counts. J. Dairy Sci. 87:3561-3573.

Miller, R. H., H. D. Norman, and L. L. M. Thornton. 2007. Somatic cell counts of milk from Dairy Herd Improvement herds during 2006. USDA AIPL Report SCC8.

Miller, R. H., H. D. Norman, and L. L. M. Thornton. 2008. Somatic cell counts of milk from Dairy Herd Improvement herds during 2007. USDA AIPL Report SCC9.

Nightingale, C., K. Dhuyvetter, R. Mitchell, and Y. Schukken. 2008. Influence of variable milk quality premiums on observed milk quality. J. Dairy Sci. 91:1236-1244.

Norman, H. D., R. H. Miller, and T. A. Cooper. 2010. Somatic cell counts of milk from Dairy Herd Improvement herds during 2009. USDA AIPL Report SCC11.

Norman, H. D., R. H. Miller, and F. A. Ross. 2009. Somatic cell counts of milk from Dairy Herd Improvement herds during 2008. USDA AIPL Report SCC10.

Oliver, S. P., R. N. Gonzalez, J. S. Hogan, B. M. Jayarao, and W. E. Owens. 2004. Microbiological Procedures for the Diagnosis of Bovine Udder Infection and Determination of Milk Quality. 4th ed. National Mastitis Council, Verona, WI.

Pantoja, J. C. F., D. J. Reinemann, and P. L. Ruegg. 2009. Associations among milk quality indicators in raw bulk milk. J. Dairy Sci. 92:4978-4987.

Wehr, H. M., and J. F. Frank. 2004. Standard Methods for Examination of Dairy Products. 17th ed. Am. Publ. Health Assoc. Inc., Washington, DC. 